\title{
sciendo
}

BULGARIAN ACADEMY OF SCIENCES

CYBERNETICS AND INFORMATION TECHNOLOGIES • Volume 18, No 2

Sofia $2018 \quad$ Print ISSN: 1311-9702; Online ISSN: 1314-4081

DOI: $10.2478 /$ cait-2018-0028

\section{Combinatorial Optimization Model for Group Decision-Making}

\author{
Dilian Korsemov ${ }^{1}$, Daniela Borissova ${ }^{1,2}$, Ivan Mustakerov $^{1}$ \\ ${ }^{1}$ Institute of Information and Communication Technologies, Bulgarian Academy of Sciences, 1113 Sofia, \\ Bulgaria \\ ${ }^{2}$ University of Library Studies and Information Technologies, 1784 Sofia, Bulgaria \\ E-mails:dilian_korsemov@abv.bg dborissova@iit.bas.bgrmustakerov@iit.bas.bg
}

\begin{abstract}
In the article a combinatorial optimization model for group decisionmaking problem is proposed. The described model relies on extended simple additive weighting model. A distinctive feature of the proposed model is consideration of the importance of experts' opinions by introducing weighted coefficient for each of experts. This allows flexible adjustment of differences in knowledge and experience of the group members responsible to determine most preferable alternative to be achieved. The numerical application is illustrated by an example for software engineering adopted from D. Krapohl. The obtained results show the practical applicability of the proposed combinatorial optimization model for group decisionmaking.
\end{abstract}

Keywords: Combinatorial optimization, group decision-making, multi-attribute decision making, simple additive weighting, experts' weights.

\section{Introduction}

The success of most of the business activities depends on selection of proper supplier of some resources. Two main factors should be taken into account in supplier selection problems: the availability of useful information for evaluation parameters and the possibility of corrupt behaviour [25]. The supplier selection is a complex problem involving not only quantitative criteria but also qualitative ones that requires subjective judgments [10]. Along with this the importance of evaluation criteria is another problem related in any selection. Other aspect in selection process is that in many cases a group of experts with different skills, experience, and knowledge relating to different aspects of selection should be used [4]. Supplier selection problem is an example for the existing difficulties for application of decision making techniques [5, 9]. An approach recognized as a suitable tool for group decision making problems is Multi-Attribute Decision Making (MADM). The MADM approach aggregates the preferences and judgments of decision makers to obtain an acceptable solution [6]. Considering all of the alternatives, evaluation criteria (attributes) and variety of opinions of group of experts with different expertise makes the group decision making process essentially complicated. The complexity of 
similar problems requires using of specific approaches to tackle with data fuzziness $[11,23]$ and to use methods of soft computing [2]. In some cases, aggregations of fuzzy relations and fuzzy numbers are used to express the weights of the criteria [19-21, 24]. Fuzzy relations and fuzzy numbers for criteria evaluations are taken into account in some models for decision making $[22,23]$. In other cases, using of linguistic expression of preferences for qualitative aspects by linguistic values is an approximate technique to express the linguistic variables [26, 29]. Expression of preferences through linguistic technique is accompanied by non-compensation of the criteria. All this is related to difficulties in aggregation of preference information by conventional additive operators. The promising direction of mathematical methods in problems of selection relies on multi-attribute utility theory (MAUT) where a utility function is used to evaluate the alternatives performance [13-15, 18]. The key idea of these methods is formulating of proper utility function to estimate all potential alternatives toward a given set of performance criteria in explicit measures. The major challenge of multi-attribute group decision making that is underestimated is to consider the individual expertise of experts and importance of their points of view about evaluations of criteria and alternatives.

In this article, a modified method based on multi-attribute utility theory is used for group decision making. A mathematical model is formulated based on modified Simple Additive Weighting (SAW) and combinatorial optimization for group decision making. The SAW is the most often used method based on the weighted average using arithmetic mean [27]. The proposed modelling approach for supplier selection takes into account the difference in knowledge and experience of each expert of the group. The rest of this article is organized as follows: Section 2 contains a description of the problem, Section 3 presents the proposed model for selection of alternative by group decision-making based on combinatorial optimization, Section 4 describes numerical testing, Section 5 contains results analysis and discussion, and conclusions are given in Section 6.

\section{Problem formulation}

The selection problems usually involve number of conflicting criteria and are recognized as important strategic decisions. The group decision making problem considered concerns a real example for software engineering $[14,18]$. The process of decision-making is to be done by a group of $K$ experts able to evaluate a predefined number $N$ of evaluation criteria and for given number $M$ of alternatives. To be more precise in selection of the most preferable alternative, the differences in level of experience and knowledge of group members are to be considered.

The goal is to select the most preferable alternative taking into account the evaluations of predefined number of alternatives toward given evaluation criteria in accordance to different point of view of experts in the group. The major difficulty is to express in a proper way the differences in skills, experience and knowledge of experts within the group to get the most preferable alternative. An integrated approach based on modification of SAW and combinatorial optimization is proposed and described in Section 3. 


\section{Combinatorial optimization model for group decision making}

In this section a mathematical model for group decision making based on modification of SAW and using of combinatorial optimization is described. Along with this an algorithm for implementation of proposed approach is given.

3.1. Modified SAW model and combinatorial optimization for group decision making

The SAW determines the best alternative using following utility function [8]:

$$
A^{*}{ }_{\text {wSM }}=\max \sum_{j=1}^{N} w_{j} a_{i j}, i=1,2, \ldots, M,
$$

where the score of the best alternative is denoted by $A^{*}{ }_{\text {wsm, }}$, number of evaluation criteria is expressed by $N$, evaluation score of $i$-th alternative toward the $j$-th criterion is denoted by $a_{i j}$, and relative importance of the $j$-th criterion is expressed by weight coefficient $w_{j}$. These coefficients should obey the restriction

$$
\sum_{j=1}^{N} w_{j}=1 \text {. }
$$

In contrast to the classic SAW method where only experts' weights for criteria importance and their evaluations towards the criteria are considered, the model proposed here takes into consideration also the importance of experts' opinions by introducing corresponding weighed coefficient for each of experts. This allows flexible adjustment of differences in knowledge and experience of the group members responsible to determine most preferable alternative.

Modification of SAW model is done by applying of combinatorial optimization through introducing binary integer variables for selection of the most preferable alternative and weighted coefficients to express the group member expertise. The proposed combinatorial optimization model is formulated as follows:

$$
\operatorname{maximize}\left(\sum_{i=1}^{M} x_{i} \sum_{k=1}^{K} \lambda^{k} \sum_{j=1}^{N} w_{j}^{k} a_{i, j}^{k}\right)
$$

subject to

$$
\begin{gathered}
\sum_{j=1}^{N} w_{j}^{k}=1, \quad k=1,2, \ldots, K, \\
\sum_{i=1}^{M} x_{i}=1, \quad x_{i} \in\{0,1\}, \\
\sum_{k=1}^{K} \lambda^{k}=1,
\end{gathered}
$$

where $\sum_{j=1}^{N} w_{j}^{k} a_{i, j}^{k}$ expresses the performance of alternatives, $i=1,2, \ldots, M$, accordingly to the point of view of different experts, $k=1,2, \ldots, K$, in the group toward each criterion, $j=1,2, \ldots, N$. The decision variables $\left\{x_{i}\right\}$ are assigned to each alternative, $i=1,2,3, \ldots, M$, to realize the selection of single alternative. The differences in the expertise of the group' members (i.e., the importance of each expert' evaluation scores) is expressed by introducing the weighted coefficients assigned to each expert of the group $\left\{\lambda^{q}\right\}, q=1,2,3, \ldots, K$. The relation (6) normalizes these coefficients 
requiring that their sum should be equal to 1 . Nevertheless it is assumed that each expert can evaluate all of the alternatives toward all of the criteria, the weighted coefficients reflect also how well the nature of the criteria is known to them.

Using of weighted coefficients to express the level of experience and relevant knowledge of group members allow more precisely to adjust the model for different specific cases of determination the most preferable alternative.

The described optimization model (3)-(6) could be transformed to select more than one preferable alternative if restriction (5) is changed as

$$
\sum_{i=1}^{M} x_{i}>1, \quad x_{i} \in\{0,1\},
$$

In such a way, the problem of single choice is transformed to the problem of multiple-choice decision making problem for selection of k-best alternatives [3, 17]. It should be noted that such modification does not determine which one of the chosen alternatives is better than others.

3.2. Algorithm for implementation of modified SAW model for group decision making

The structure of proposed algorithm for implementation of modified SAW model is composed of 9 stages including a stage for determining the different expertise of group members. The first step concerns (1) description of the existing problem; followed by (2) determining of acceptable alternatives appropriate to cope with the problem's goal; (3) identifying of suitable evaluation criteria; (4) determining of a group of competent experts to evaluate the alternatives toward evaluation criteria; (5) determining of corresponding weighted coefficients to express the group members' knowledge and experience; (6) determining of relative importance between criteria in accordance to the point of view of each expert; (7) evaluation of alternatives toward criteria by all experts - depending on the units of dimension for evaluation criteria at this stage a normalization could be used and normalization schemes depend on whether criteria are maximized or minimized [30]; (8) formulation of combinatorial optimization task; (9) solution of the optimization task and determining of the most preferable alternative.

In practice, the group decision-making process is managed by a leader of the group. $\mathrm{He} / \mathrm{she}$ is usually responsible to identify the possible alternatives and essential criteria for evaluation. He/she also determines the weighted coefficients that express the group members' knowledge and experience. The leader can be a person authorized to make the final decision or to present the most appropriate alternative to higher management.

\section{Numerical testing}

This section provides an illustrative application of the proposed modification of SAW model and extended algorithm for its implementation in the context of group decision-making, as described in Section 3. 


\begin{tabular}{|c|c|c|c|c|c|c|c|c|}
\hline \multirow{2}{*}{ 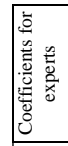 } & & $\overline{0}$ & $\stackrel{0}{2}$ & $\stackrel{8}{0}$ & $\stackrel{d}{0}$ & & $\stackrel{\infty}{3}$ & $\stackrel{\circ}{\circ}$ \\
\hline & & $\frac{6}{0}$ & $\frac{5}{0}$ & $\frac{5}{0}$ & $\frac{5}{0}$ & & $\frac{\circ}{0}$ & $\frac{\circ}{0}$ \\
\hline & 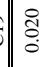 & $\mid$\begin{tabular}{l}
0 \\
\hdashline
\end{tabular} & : & 总 & $\begin{array}{ll}0 \\
0 \\
0\end{array}$ & 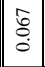 & 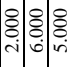 & \\
\hline & 导 & 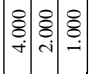 & 管 & 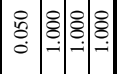 & $\begin{array}{l}0 \\
0 \\
0 \\
0\end{array}$ & 要 & 8 & \\
\hline & 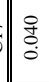 & : & : & & & 递 & & \\
\hline & 这 & क्षृ: & 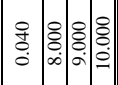 & & & 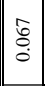 & 8 & 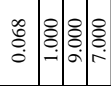 \\
\hline & : & : & 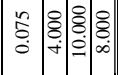 & $\mid \begin{array}{l}0 \\
0 \\
0 \\
0 \\
0\end{array}$ & & 要 & ㅇㅇㅇ & 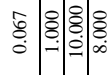 \\
\hline & 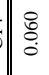 & 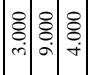 & | & & & 要 & & \\
\hline & 送 & $\begin{array}{l}8 \\
\vdots\end{array}$ & 8 & & 象 & 然 & 8 & \\
\hline & : & خृ: & 旁 & 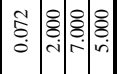 & $\left(\begin{array}{c}2 \\
0 \\
0\end{array}\right.$ & 总 & 8 & 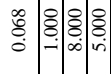 \\
\hline & 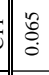 & \begin{tabular}{|c|c|c|c|c|c|} 
& 0 \\
& 0 \\
\end{tabular} & \begin{tabular}{l|l}
0 \\
0 \\
0
\end{tabular} & & 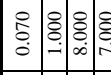 & \begin{tabular}{|l|} 
\\
0 \\
0
\end{tabular} & & \\
\hline & م气 & \begin{tabular}{l|l}
$\vdots$ \\
\hdashline
\end{tabular} & : & & & 竞 & & \\
\hline 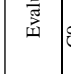 & 告 & \begin{tabular}{l|l}
0 \\
$\vdots$
\end{tabular} & & & 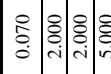 & 焉 & & \\
\hline & . & 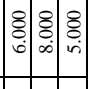 & 瓷 & & & $\begin{array}{ll}0 \\
\\
0 \\
0 \\
0\end{array}$ & 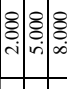 & \\
\hline & 告 & क्षे: & $\mid \begin{array}{c}0 \\
0 \\
:\end{array}$ & & & 竞 & & \\
\hline & 气̊. & $\begin{array}{l}8 \\
\vdots\end{array}$ & 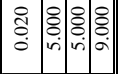 & & $\left(\begin{array}{c}n \\
0 \\
0\end{array}\right.$ & ã & & 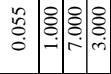 \\
\hline & 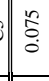 & 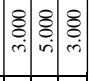 & 毫 & & 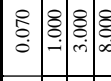 & $\begin{array}{l}5 \\
0 \\
0 \\
\end{array}$ & t్ & 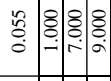 \\
\hline & : & $\begin{array}{l}8 \\
0 \\
:\end{array}$ & & & 尊 & ầ & & 导 \\
\hline & : & : & & & 突: & $\mid$ & & 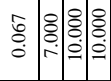 \\
\hline & : & 8 & 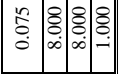 & हृ: & 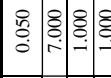 & 告 & छ్రి: & 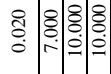 \\
\hline & ठ & : & 离 & 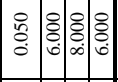 & 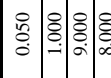 & â. & 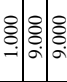 & ¿̊: \\
\hline 紊递 & & 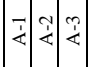 & 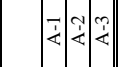 & 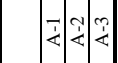 & 798 & & दों & \\
\hline 产 & $\|=$ & $\overline{\dot{4}}$ & $\Longrightarrow$ & $=3$ & 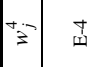 & $\equiv$ & 㞻 & 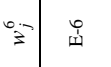 \\
\hline
\end{tabular}


The numerical example for software engineering adopted from [14] is used to verify the proposed approach and algorithm. The problem is composed of nineteen evaluation criteria as follows: (1) enforces process accountability; (2) addresses horizontal reporting; (3) addresses vertical reporting; (4) reinforces standards of practice; (5) effectively handles the gathering of local requirements; (6) effectively handles the gathering of enterprise requirements; (7) provides project visibility to contract project management office; (8) provides project visibility to government project management office; (9) provides visibility to local site leads; (10) provides project management oversight for projects; (11) provides mechanism to efficiently assign resources; (12) enforces requirements management; (13) provides specific requirements approval and prioritization; (14) promotes de-confliction of requirements; (15) aligns work to Software resources; (16) manages and operates resources more efficiently; (17) will be supported by local customers; (18) development environment is reachable by all resources; and (19) realign resources to handle surge. This problem is entrusted to the group of six authorized experts (E-1, E-2, E-3, E-4, E-5, E-6) to select the most preferable alternative of three possible alternatives (A-1, A-2, A-3). Each expert of the group determines the importance of all criteria by assigning of corresponding weighted coefficients in accordance to his point of view and determines the evaluations of alternatives toward the given criteria.

All of the described above data together with normalized experts' evaluations of the alternatives performance in regards to the given criteria are shown in Table 1.

\section{Results analysis and discussions}

The numerical testing is done on the basis of a real-life problem for software engineering. The proposed mathematical model (3)-(6) and normalized data about alternatives evaluations from Table 1 are used to formulate combinatorial optimization tasks. The LINGO solver, version 12 , is used to solve optimization tasks. The obtained results are shown in Table 2.

Table 2. Solution results

\begin{tabular}{|c|c|c|c|c|c|c|c|c|}
\hline Case & \multicolumn{5}{|c|}{$\begin{array}{c}\text { Weighted coefficients for expertise } \\
\text { of the group members }\end{array}$} & $\begin{array}{c}\text { Selected one } \\
\text { preferable } \\
\text { alternative }\end{array}$ & $\begin{array}{c}\text { Selected two } \\
\text { preferable } \\
\text { alternatives }\end{array}$ \\
\cline { 2 - 6 } & E-1 & E-2 & E-3 & E-4 & E-5 & E-6 & A-2 & A-2 \& A-3 \\
\hline Case-1 & 0.167 & 0.167 & 0.167 & 0.167 & 0.166 & 0.166 & A-3 & A-2 \& A-3 \\
\hline Case-2 & 0.110 & 0.120 & 0.050 & 0.240 & 0.380 & 0.100 & . \\
\hline
\end{tabular}

The flexibility of the described approach is illustrated by using of two different cases for group member's evaluations' importance. In Case-1 all experts are considered as equivalent in their opinions. This assumption is identical to the examples described in $[14,18]$. The comparison of numerical test results for the Case-1, identical to $[14,18]$, shows a complete match in determining the most preferred alternative, namely alternative A-2. This proves the correctness of the proposed optimization model (3)-(6).

In Case-2, different weighted coefficients representing different level in expertise of group members are used. The evaluations of experts E-4 and E-5 are 
considered as most important, followed by expert E-6 that has some middle significance and E-1, E-2 and E-3 opinions have the smallest value. The solution in this second case determines the most preferable alternative - A-3 as shown in last row of Table 2 .

Numerical testing for determination of two preferable alternatives by using constraint ( $\left.5^{*}\right)$ instead of (5), determines alternatives A-2 and A-3 for both cases of weighted coefficients for the experts (Table 2). In this solution it is unknown which of the selected alternatives is better, but both of alternatives A-2 and A-3 are surely better than alternative A-1.

It should be mentioned, that using of weighted coefficients to express the level of experience and relevant knowledge of group members allow more precise and objective assessment in determining of the most preferable alternative.

\section{Conclusion}

The widely used classic SAW approach is modified to cope with group decisionmaking. The single utility function of SAW in extended by using of binary integer variables to determine the most preferable alternative as solution of combinatorial optimization task. Another essential modification in utility function of SAW takes into account differences in knowledge and experience of group members by introducing weighted coefficients for each member. The proposed modified SAW in group decision-making environment is realized via modified algorithm for implementation of modified SAW. This algorithm is composed of 9 stages including a stage for determination of different expertise of group members. Another kind of utility functions can be used in the proposed algorithm.

Using of combinatorial optimization in the described approach does not require increasing of computational time but adds flexibility in getting the most preferable alternative considering group members expertise. This allows more precise and objective approach to determine the most preferable alternative using different points of view of group members and their relevant level of experience and knowledge. The practical usability was confirmed by numerical testing on an example of a real-life problem for software engineering problem.

The planned future investigations are on the influence of fuzziness in estimations of alternatives and criteria by group members on the determination of most preferable alternative.

\section{References}

1. A bdullah, L., C. W. R. Ad a wi y a h. Simple Additive Weighting Methods of Multi Criteria Decision Making and Applications: A Decade Review. - International Journal of Information Processing and Management, Vol. 5, 2014, No 1, pp. 39-49.

2. A n g e lo v a, V. Investigations in the Area of Soft Computing. Targeted State of the Art Report. Cybernetics and Information Technologies. Vol. 9, 2009, No 1, pp. 18-24.

3. B o r i s s o v a, D. Group Decision Making for Selection of k-Best Alternatives. - Compt. Rend. Acad. bulg. Sci., Vol. 69, 2016, No 2, pp. 183-190. 
4. B or i s s o va, D., I. Mu s t a k e r o v, D. Kor s e mo v. Business Intelligence System via Group Decision Making. - Cybernetics and Information Technologies, Vol. 16, 2016, No 3, pp. 219-229.

5. Ch a i, J., J. N. K. Li u, E. W. T. Ng a i. Application of Decision-Making Techniques in Supplier Selection: A Systematic Review of Literature. - Expert Systems with Applications, Vol. 40, 2013, No 10, pp. 3872-3885.

6. Ch e n, F., M. Li, H. W u. GACRM: A Dynamic Multi-Attribute Decision Making Approach to Large-Scale Web Service Composition. - Applied Soft Computing, Vol. 61, 2017, pp. 947-958

7. De B o e r, L., E. L a b r o, P. M or 1 a c c h i. A Review of Methods Supporting Supplier Selection. - European Journal of Purchasing \& Supply Management, Vol. 7, 2001, No 2, pp. 75-89.

8. Encyclopedia of Electrical and Electronics Engineering. Vol. 15. J. G. Webster, Ed. New York, John Wiley \& Sons, 1998, pp. 175-186.

9. H o, W., X. X u, P. K. D e y. Multi-Criteria Decision Making Approaches for Supplier Evaluation and Selection: A Literature Review. - European Journal of Operational Research, Vol. 202, 2010, No 1, pp. 16-24.

10. I g a r a h i, M., L. B o e r, O. M i c h e l s e n. Investigating the Anatomy of Supplier Selection in Green Public Procurement. - Journal of Cleaner Production, Vol. 108, 2015, Part A, pp. 442-450.

11. I 1 i e va, G. Group Decision Analysis with Interval Type-2 Fuzzy Numbers. - Cybernetics and Information Technologies, Vol. 17, 2017, No 1, pp. 31-44.

12. K a 1 i s z e w s k i, I., D. P o d k o p a e v. Simple Additive Weighting - A Metamodel for Multiple Criteria Decision Analysis Methods. - Expert Systems with Applications, Vol. 54, 2016, pp. 155-161.

13. K e e n e y, R. L., H. R a iff a, 1993. Decisions with Multiple Objectives: Preferences and Value Trade-Offs. New York, Wiley. 569 p.

14. K r a p o h 1, D. A Structured Methodology for Group Decision Making. 2014. http://www.augmentedintel.com/wordpress/index.php/a-structured-methodology-forgroup-decision-making/

15. L e e, L., R. Anderson. A Comparison of Compensatory and Non-Compensatory Decision Making Strategies in IT Project Portfolio Management. - International Research Workshop on IT Project Management 2009. http://aisel.aisnet.org/irwitpm2009/9

16. Mimovic, P. Application of Multi-Criteria Analysis in the Public Procurement Process Optimization. - Economic Themes, Vol. 54, 2016, No 1, pp. 103-128.

17. Mustakerov, D. Borissova, E. Bantutov. Multiple-Choice Decision Making by Multicriteria Combinatorial Optimization. - International Journal Advanced Modeling and Optimization, Vol. 14, 2012, No 3, pp. 729-737.

18. M u s t a k e ro v, I., D. B or is s o v a. A Web Application for Group Decision-Making Based on Combinatorial Optimization. - In: Proc. of 4th International Conference on Information Systems and Technologies, March 22-24, 2014, Valencia, Spain, pp. 46-56.

19. P e n e v a, V., I. P o p c h e v. Aggregation of Fuzzy Relations Using Weighting Function. - Compt. Rend. Acad. bulg. Sci., Vol. 60, 2007, No 10, pp. 1047-1052.

20. P e n e va, V., I. P o p ch e v. Aggregation on Fuzzy Numbers in a Decision Making Situation. Cybernetics and Systems, Vol. 32, 2001, No 8, pp. 871-885.

21. P e n e va, V., I. P o p che v. Fuzzy Criteria Importance Depending on Membership Degrees of Fuzzy Relations. - Comptes Rendus de l'Academie bulgare des Sciences, Vol. 61, 2008, No 5, pp. 579-584.

22. P e n e v a, V., I. P o p c h e v. Models for Decision Making by Fuzzy Relations and Fuzzy Numbers for Criteria Evaluations. - Compt. Rend. Acad. bulg. Sci., Vol. 62, 2009, No 10, pp. 1217-1222.

23. Peneva, V., I. Popchev. Multicriteria Decision Making Based on Fuzzy Relations. Cybernetics and Information Technologies, Vol. 8, 2008, No 4, pp. 3-12.

24. P o p c h e v, I., V.P e n e v a. An Algorithm for Comparison of Fuzzy Sets. - Fuzzy Sets and Systems, Elsevier Science Publishers, North-Holland, Amsterdam, Vol. 60, 1993, No 1, pp. 59-65. 
25. S c i a c a l e pore, F., M. F a lag ari o, N. Cost ant in o, R. Pi e trof or t e. Multi-Criteria Bid Evaluation of Public Projects. - In Proc. of Management and Innovation for a Sustainable Built Environment, Amsterdam, The Netherlands, 2011.

http://resolver.tudelft.nl/uuid:6d5eb0f6-c4b8-4425-bbf9-473209a522d0

26. T a n, C., D. D. W u, B. M a. Group Decision Making with Linguistic Preference Relations with Application to Supplier Selection. - Expert Systems with Applications, Vol. 38, 2011, No 12, pp. 14382-14389.

27. Triant a ph y 11 o u, E. Multi-Criteria Decision Making Methods. In: Multi-Criteria Decision Making Methods: A Comparative Study. - Applied Optimization, Vol. 44, Springer, Boston, MA, 2000. 290 pages.

28. V e la s qu e z, M., P. T. He ste r. An Analysis of Multi-Criteria Decision Making Methods. International Journal of Operations Research, Vol. 10, 2013, No 2, pp. 56-66.

29. W a n, S.-P, G. L. X u, J. Y. D o n g. Supplier Selection Using ANP and ELECTRE II in Interval 2Tuple Linguistic Environment. - Information Sciences, Vol. 385-386, 2017, pp. 19-38.

30. Y o o n, K. P., Ch-L. Hw an g. Multiple Attribute Decision Making: An Introduction. SAGE Publications, 1995, 75 pages.

Received 16.03.2018; Second Version 08.05.2018; Accepted 21.05.2018 